\title{
Processors' Experience in the Use of Flash Dryer for Cassava-derived Products in Nigeria
}

\section{OPEN ACCESS}

Edited by:

Guadalupe Virginia Nevárez-Moorillón,

Autonomous University of

Chihuahua, Mexico

Reviewed by:

German Cuevas,

University of Guanajuato, Mexico

Samuel Bernardo,

Autonomous University of

Chihuahua, Mexico

*Correspondence:

Makuachukwu Gabriel Ojide

embracegod1@yahoo.com;

makuachukwu.ojide@funai.edu.ng

Specialty section:

This article was submitted to

Sustainable Food Processing,

a section of the journal

Frontiers in Sustainable Food Systems

Received: 06 September 2021

Accepted: 15 December 2021

Published: 17 February 2022

Citation:

Ojide MG, Adegbite S, Tran T, Taborda LA, Chapuis A, Lukombo S, Totin E, Sartas M, Schut M, Becerra

Lopez-Lavalle LA, Dufour D and

Abass A (2022) Processors'

Experience in the Use of Flash Dryer

for Cassava-derived Products in

Nigeria.

Front. Sustain. Food Syst. 5:771639.

doi: 10.3389/fsufs.2021.771639

\author{
Makuachukwu Gabriel Ojide ${ }^{1 *}$, Suraju Adegbite ${ }^{2}$, Thierry Tran ${ }^{3,4,5}$, \\ Luis Alejandro Taborda ${ }^{3,6}$, Arnaud Chapuis ${ }^{4,7,8}$, Simon Lukombo ${ }^{9}$, Edmond Totin ${ }^{10}$, \\ Murat Sartas ${ }^{9,11}$, Marc Schut ${ }^{11,12}$, Luis Augusto Becerra Lopez-Lavalle ${ }^{3}$, \\ Dominique Dufour ${ }^{3,4,8}$ and Adebayo Abass $^{9}$
}

\begin{abstract}
${ }^{1}$ Department of Economics and Development Studies, Alex Ekwueme Federal University Ndufu-Alike (AE-FUNAI), Abakaliki, Nigeria, ${ }^{2}$ Department of Project Development and Design (PDD), Federal Institute of Industrial Research, Oshodi (FIIRO), Lagos, Nigeria, ${ }^{3}$ Alliance of Bioversity and International Center for Tropical Agriculture, Consultative Group for International Agricultural Research Program on Roots Tubers and Bananas (RTB), Cali, Colombia, ${ }^{4}$ Centre de coopération Internationale en Recherche agronomique pour le Développement, UMR QualiSud, Montpellier, France, ${ }^{5}$ Centre de coopération Internationale en Recherche agronomique pour le Développement, UMR QualiSud, Cali, Colombia, ' Intellectual Property, Innovation and Extension Department, Palmira Campus, National University of Colombia, Bogotá, Colombia, ${ }^{7}$ Centre de coopération Internationale en Recherche agronomique pour le Développement, UMR QualiSud, Saint Louis, Sénégal,

${ }^{8}$ Qualisud, University of Montpellier, Centre de coopération Internationale en Recherche agronomique pour le Développement, Montpellier SupAgro, University of Avignon, University of La Réunion, ${ }^{9}$ International Institute of Tropical Agriculture (IITA), Consultative Group for International Agricultural Research Program on Roots Tubers and Bananas (RTB), Ibadan, Nigeria, ${ }^{10}$ Ecole de Foresterie Tropicale, Université Nationale d'Agriculture, Ketou, Bénin, ${ }^{11}$ Technology and Innovation Unit, Department of Social Sciences Knowledge, Wageningen University, Wageningen, Netherlands,

${ }^{12}$ International Institute of Tropical Agriculture (IITA), Consultative Group for International Agricultural Research Program on Roots Tubers and Bananas (RTB), Kigali, Rwanda
\end{abstract}

This study was designed and carried out to ascertain the situation and perceptions of end users of cassava flash drying equipment in Nigeria with the aim of giving suggestions to policies and approaches for improved technology. Forty-one processing firms were selected and interviewed. Descriptive analyses were used and a logistic regression model was estimated. The results revealed that $49 \%$ of the firms stopped using their flash dryers due to the low demand for high-quality cassava flour (HQCF) resulting from the high cost of processing occasioned by an inefficient heat-generating component. The estimated model provides evidence that cost effectiveness $(p<0.05)$ and energy cost $(p<0.10)$ are the two major determinants of the continuous usage of flash dryers in the study area. Forty-one percent of the firms indicated willingness to pay for any technical adjustment of their flash dryers, supposing such adjustment would improve on drying and the energy efficiency of the equipment up to $40 \%$. The study recommends that machine fabricators in Nigeria and other African countries should be trained on the production of energy- and cost-efficient small-scale flash dryers. Again, the design and commercialization of flash dryers that can be mounted on mobile trucks for farm-gate processing should be encouraged to facilitate farm-gate processing, thereby reducing postharvest losses resulting from transporting perishable and bulky roots over a long distance.

Keywords: energy efficiency, farm-gate, flour millers, postharvest, production capacity, willingness to pay 


\section{INTRODUCTION}

One of the major root crops with increasing food and industrial applications is cassava, especially in several tropical and subtropical countries. Globally, cassava output increased from 75 million ton to 282 million ton between 1961-1963 and 2016-2018. Africa contributes a greater proportion (between 54 and $58 \%$ ) of the world's cassava production, with Nigeria as the largest producer. Over the last three decades, the total cassava output in Sub-Saharan Africa (SSA) exceeded that of other major food commodities. Cassava roots have a high moisture content at harvest (typically $60-75 \%$ wet basis), which makes it highly perishable due to physiological processes that take place from 2 to 3 days of harvest, which are subsequently followed by microbial decay (Beeching et al., 1993; Scott, 2021). It is, therefore, expedient to process cassava root soon after harvesting. In a many tropical countries, there is an increasing interest in the development of cassava processing activities. This is because such processing activities are considered as essential to increasing the economic benefits derivable from fresh cassava root production activities. Interest in the development of cassava processing activities has intensified since the 2008 food crisis, as it has become needful to support agricultural processing activities as a strategy toward reducing the reliance of such countries on imported staple foods, thereby limiting their exposure to price fluctuations in the international markets and improving national food security (Chapuis et al., 2017). In most sub-Saharan African countries, cassava is grown primarily by smallholder farmers and is a significant source of calories for the local population.

Nevertheless, the short shelf life of cassava, which is associated with the poor technology infrastructure in the region, results in significant postharvest losses. The use of small-scale cassava processing machines could reduce these losses (Precoppe et al., 2017). The processing of cassava roots also provides opportunities to add value to raw roots by transforming them into different primary and secondary products of economic significance. Starch and flour are the two vital primary products derivable from cassava roots traded globally. These two products are dried products often marketed or stored at low moisture levels (10-14\%, wet basis) (Shittu et al., 2016).

Globally, several efforts are being made by various institutions, projects, programs, the private sector, and governments to enhance the quality and utilization of cassava flour and starch. One of such efforts is the introduction of the flash dryer technology for the accelerated production of high-quality cassava flour (HQCF) and high-quality starch. HQCF is a raw material for the production of glucose syrup, bakery products, and industrial alcohol. Flash dryers are state-of-the-art equipment especially designed to rapidly dry semi-processed wet cassava obtained from grating and dewatering of cassava roots, within about $3 \mathrm{~s}$, into HQCF that is ready for human and commercial use (Chapuis et al., 2017; Africa Innovations Institute [AfrII], 2018). Flash dryers are also used to produce dried starch from wet cassava starch. Flash drying is an alternative to sun drying, which has many limitations. Although sun drying is less expensive, it requires the availability of a large space of land and a long drying period, which exposes the product to contamination, and its efficiency depends on weather conditions. The increasing demand for more quality dried cassava products requires a more reliable drying process, which a flash dryer offers. This technology reduces fungal, bacterial, and dust contaminations, thereby reducing health risks to consumers. Flash drying is energy-intensive and, therefore, relatively more costly than sun drying. Thus, flash dryers must be energy-efficient (Chapuis et al., 2018). Abass et al. (2017a) and Abass et al. (2017b) have shown that the adoption of a mechanized cassava processing system can transform primary production activities, in turn leading to higher incomes and reduced poverty levels among cassava farmers in many African countries, including Zambia and Uganda. IITA (2006) asserted that Nigeria needs more than 300 units of flash dryers with a capacity of 3-5 ton/day to meet the current demand for cassava flour. However, it was noted that locally manufactured flash dryers were not yet efficient. The high operational cost of the technology can mean the difference between profitability and losses and, hence, narrows down the tendency to adopt the technology given the small profit margins in HQCF and starch production.

Consequently, cassava farmers and processors in Nigeria and other African countries have sought cost-effective and efficient flash dryers. Such improved technology will substantially reduce postharvest losses by increasing the outputs of cassava flour and starch, increasing value addition to the crop for income and employment generation and improving farmers' livelihoods. Currently, cassava processors, equipment manufacturers, national agricultural research institutions, and private investors in different countries [including Nigeria, DR Congo (DRC), Colombia, Ghana, Cameroon, Tanzania, Peru, Uganda, Philippines, Indonesia, etc.] are in a quest to develop an improved version of the small-scale flash dryer. Kuye et al. (2017) asserted that the design and fabrication of processing equipment in most developing countries, such as Nigeria, face several challenges due to the lack of appropriate equipment and tools. As a result, most locally designed and fabricated flash dryers are noisy and ineffective. Therefore, Precoppe et al. (2016) emphasized the need to improve the energy performance of small-scale dryers for processing cassava in Africa.

Cassava processing firms in Africa are mostly of small or medium size; a few large processing industries, using state-ofthe-art flash dryers, operate in South and West Africa. Flash drying equipment, for small-sized enterprises, should have low operating costs and capital and should be easy to build and simple to operate (Precoppe et al., 2020). In Nigeria, about 157 cassava processors invested in "first-generation" flash dryers between 2006 and 2016. These first-generation flash dryers were those fabricated before the first innovations to improve the efficiency of the heat exchanger. Unfortunately, not a lot of the machines are still in use due to their low energy efficiency and subsequent high operational costs (The Nation Newspaper, 26/09/2016; http://thenationonlineng.net/resuscitating-localindustries-antidote-recession/). Several factors occasion these high operational costs. The primary factor is the cost of fueling the burner to heat the drying air through a heat exchanger; others include the location of factories in urban centers benefitting from better access to grid electricity, but far from the source of fresh cassava. For cassava roots, being perishable within $48 \mathrm{~h}$ after harvest, losses occur before the roots get to the factory. 
Delay in receiving enough cassava roots for processing also impedes optimal utilization of the flash dryer (Ampah et al., 2017). Therefore, the scaling up of energy-efficient small-scale (3-10 ton product/day) flash dryers in Nigeria has become necessary for the sustenance of the enhanced cassava value chain in the country (Chapuis et al., 2017, 2018). Naturally, the scaling up of energy-efficient small-scale flash dryers in Nigeria will trickle down on many African countries importing flash dryers manufactured in Nigeria (https://agrinatura-eu.eu/news/ upscaling-the-nigerian-flash-drying/).

Therefore, this study aimed to examine the experience and perception of end users of flash dryers in Nigeria. Specifically, the study sought to achieve the following objectives in the context of Nigeria:

- Determine the proportion of flash dryers still being used by processors and the frequency of usage, as well as the reasons for the non-usage of flash dryers;

- Examine the technical characteristics/specifications of flash dryers in terms of energy sources for heat exchanger, the average temperature in the flash dryer, installed production capacity, and the processors' perception of the performance of the flash dryer;

- Determine the major factors influencing continuous (or otherwise) use of flash dryers in Nigeria and a way of understanding the potential challenges of flash dryer users in other countries (such as Tanzania, Zambia, Madagascar, and DRC) where Nigerian-made flash dryers have been exported over the last decades; and

- Ascertain the willingness of the processors to pay for improvements to the drying and energy efficiency of existing flash dryers.

It is expected that the output of this study will enhance strategic planning toward determining if and what improvements are needed to further appropriate the potential benefits of flash dryers in Nigeria and other emerging economies. The study results will also facilitate benchmarking of improved experience among current and future adopters of the energy-efficient smallscale flash dryers in Nigeria.

How individuals or firms adopt technological innovations has inspired much research across many disciplines. Straub (2009) examined adoption theories, such as Rogers's innovation diffusion theory, the technology acceptance model, the concernsbased adoption model, and the unified theory of acceptance and use of technology. Other theories proposed to explain consumers' adoption of new technologies were identified by Lai (2017). These include, but are not limited to, the theory of task-technology fit (TTF), theory of planned behavior (TPB), the theory of reasonable action (TRA), decomposed theory of planned behavior, final version of the technology acceptance model (TAM), and the extended technology acceptance model (TAM2). In light of these several theories, Straub (2009) suggests that technology adoption is a rather complex, developmental, and inherently social process influenced by individuals' perceptions of the technology. Therefore, to successfully facilitate technology adoption, the perceptions of current and potential adopters must be addressed.
This was captured in the TAM introduced by Fred Davis in 1986 (cited in Lai 2017). TAM is an adaptation of the theory of reasonable action designed explicitly for modeling individuals' perceptions of technologies. This informed the study on the perceptions of end users of flash dryers regarding facilitating continuous and broader adoption of the technology in Nigeria. The theory stipulates that perception is a major factor influencing technology adoption. An individual's "wrong" or negative perception could negatively impact the industry. In Figure 1, which displays a graphical representation of TAM, "perceived usefulness" refers to potential users' subjective likelihood that the technology will improve a process or action. "Perceived ease of use" is defined as the degree to which a potential user expects the technology to be efficient. The assumption that the perception of a potential user could be influenced by other external factors $\left(X_{1}\right.$, $X_{2} \ldots X_{n}$ ) is also captured in TAM as external variables.

Several empirical studies have been conducted on the adoption of technological innovations, especially in the agricultural sector. However, the majority of these studies have focused on the effects and determinants of technology adoption (Johnson et al., 1999; Adesina and Chianu, 2002; Wossen et al., 2019). A major study on the development and trials of a small-capacity pilot flash dryer for cassava-derived products was carried out by Chapuis et al. (2018). Some of the studies in Africa on flash dryers included the performance evaluation of a locally fabricated mini cassava flash dryer by Ajao and Adegun (2009) and an assessment of a 6-cyclone flash dryer in Ghana by Ampah et al. (2017). Nonetheless, there is an apparent dearth of literature on the experience of end users of flash dryers in Africa, especially in Nigeria, hence the need for this study.

\section{RESEARCH METHOD}

A semi-structured questionnaire was designed and used to collect the research data. Related literature was reviewed to design the questionnaire, and key informants in the cassava value chain in Nigeria were consulted. Based on the literature review and feedback from key informants, a semi-structured questionnaire was designed, vetted by the authors and adopted for the study. Aside from the general information about the processing firm and the respondents, the questionnaire provided information on experiences in the use of flash dryers, technical parameters and performance of the machine, market prospects, and willingness to pay for improved flash dryers. The questions on willingness to pay for improvements to flash dryers were designed based on scenario analysis. The questionnaire was programmed using Surveybe software (an off-line questionnaire administration software). This software provides logic flow and controls that enhance data quality.

Three enumerators and one supervisor conducted the survey. The three enumerators hold a Master's degree and were selected because of their experience in primary data collection and familiarity with the selected geopolitical zone. Before the fieldwork, the survey team was trained using a backward approach. Firstly, the survey team reviewed the questionnaire individually. Secondly, they examined two flash dryers in order to familiarize themselves with the components and operations of 


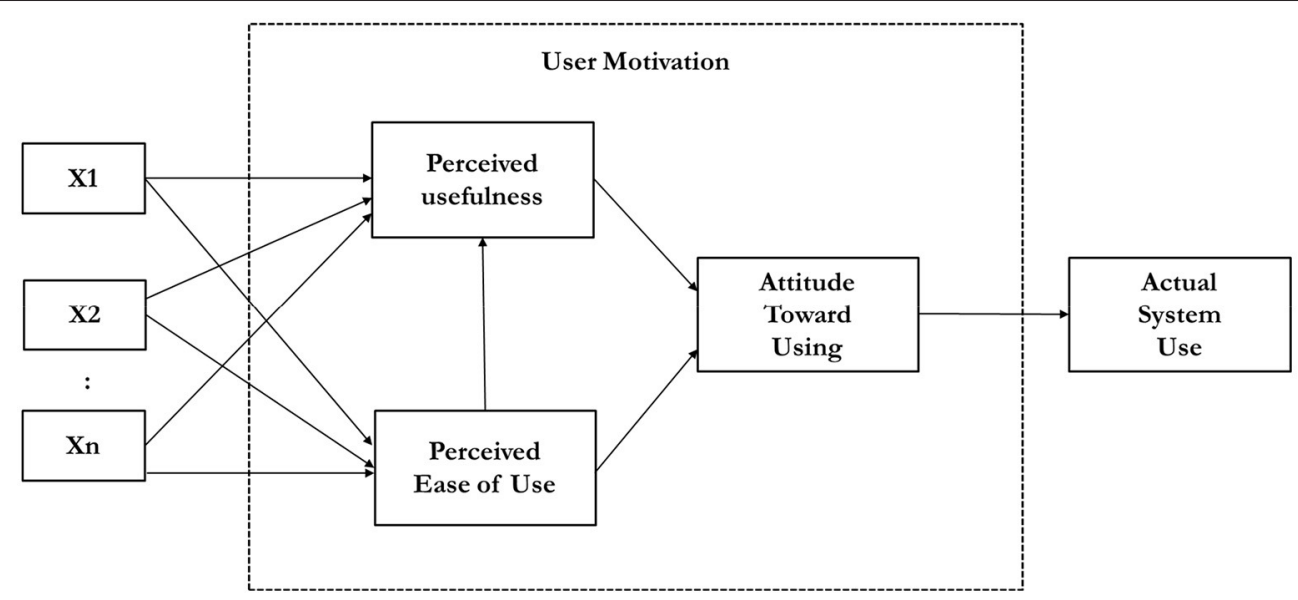

FIGURE 1 | The technology acceptance model (Davis, 1986; cited in Lai, 2017).

the equipment. After the site visits, a detailed group review of the questionnaire was done by the team to agree on the interpretation of each question. Given the site visits, it was easier for the survey team to relate the questions with realities during the team review of the questionnaire. Immediately after the training, the survey started on November 15, 2019 and ended on December 9, 2019.

Multistage sampling with the snowball technique was adopted (Oregon State University, 2010). Firstly, the Western Region of Nigeria (with focus on Lagos, Oyo, Ogun, Kwara, and Osun States) was purposively selected as the study area. The selected states are among the leading states in cassava production in the cassava-growing regions of Nigeria. The target population was cassava and starch processors with flash dryers-whether functional or not. A list of the processors supposedly using cassava or starch flash dryers was obtained from the International Institute of Tropical Agriculture (IITA) Ibadan, Federal Institute of Industrial Research, Oshodi (FIIRO), and Department of Agricultural Development Programme (ADP) in the states within the region. An additional list was obtained from local fabricators of cassava and starch flash dryers. The collected lists of processors within the selected States were pooled together to form the sampling frame of the study. As part of the presurvey activities, the survey team made an effort to contact all the processors listed in the sampling frame. Many of them could not be reached mainly because they have gone out of business. About 28 processors were contacted, although some were no longer in business. The survey team visited and interviewed the 28 processors who were contacted. Following the snowball technique, each processor interviewed was asked to identify any other processor who has a flash dryer (functional or not) within the target region. Thus, on the whole, 41 processors were identified and interviewed. Data obtained from these processors were used for the study.

In light of the TAM (Davis, 1986; cited in Lai, 2017), a logistic regression model was used to estimate the usage of a flash dryer or otherwise given the perceptions of the processors. This is because the endogenous variable has a binomial distribution. The fundamental assumption of the model is that the natural logarithm of the odds ratio is linearly related to the exogenous covariates. Odds ratio refers to the ratio of the probability of an event occurring to the probability of that event not occurring (Runyi, 2017). With a binary response variable $W$ and an exogenous variable (covariate) $X$,

$$
\operatorname{Let} \pi(x)=P(W=1 / X=x)=1-P(W=0 / X=x)
$$

Thus, the logistic regression model is as depicted in Equation 2.

$$
\pi_{i}=\frac{\exp \left(\sum_{j=1}^{p} \beta_{j} X_{i j}\right)}{1+\exp \left(\sum_{j=1}^{p} \beta_{j} X_{i j}\right)}
$$

A mathematical model with a set of exogenous variables was used to predict a logit transformation of the endogenous variable. Given that $p$ is the proportion of flash dryer usage responses with an outcome of $1,1-p$ is the probability of a response being 0 . The ratio " $p /(1-p)$ " is the odds, and the logit is the logarithm of odds or just log of odds. The logit transformation is as depicted in Equation 3.

$$
l=\log i t(p)=\ln \left(\frac{p}{1-p}\right)
$$

In this model, the difference between two log odds will be used to compare two proportions, such as flash dryers still in use and not in use. This difference is as represented, arithmetically, in Equations 4-8.

$$
\begin{array}{r}
l_{1}-l_{2}=\operatorname{logit}\left(p_{1}\right)-\operatorname{logit}\left(p_{2}\right) \\
=\ln \left(\frac{p_{1}}{1-p_{1}}\right)-\ln \left(\frac{p_{2}}{1-p_{2}}\right) \\
=\ln \left(\frac{\left(\frac{p_{1}}{1-p_{1}}\right)}{\left(\frac{p_{2}}{1-p_{2}}\right)}\right)
\end{array}
$$

This difference is known as log of the odds ratio or merely the odds ratio. It compares the proportions across groups 
TABLE 1 | Variables used in the logistic model.

\begin{tabular}{|c|c|c|c|}
\hline Variables & Code & Type & Definition \\
\hline Flash dryer usage & Fduse & Dummy & 0 if flash dryer is no longer in use; 1 if flash dryer is still in use \\
\hline Drying efficiency & dryEff & Ordinal & $\begin{array}{l}1 \text { if firm rated drying efficiency lowest; } 5 \text { if firm rated drying efficiency highest. The higher } \\
\text { the rating, the better. }\end{array}$ \\
\hline Uniform drying of product & uniformDry & Ordinal & $\begin{array}{l}1 \text { if firm rated uniform drying of product lowest; } 5 \text { if firm rated uniform drying of product } \\
\text { highest. The higher the rating, the better. }\end{array}$ \\
\hline Cost effectiveness & costEff & Ordinal & $\begin{array}{l}1 \text { if firm rated cost effectiveness lowest; } 5 \text { if firm rated cost effectiveness highest. The } \\
\text { higher the rating, the better. }\end{array}$ \\
\hline Overall quality of final product & oquality & Ordinal & $\begin{array}{l}1 \text { if firm rated overall quality of final product lowest; } 5 \text { if firm rated overall quality of final } \\
\text { product highest. The higher the rating, the better. }\end{array}$ \\
\hline Cost of labor & costLab & Ordinal & $\begin{array}{l}1 \text { if firm rated cost of labor lowest; } 5 \text { if firm rated cost of labor highest. The lower the } \\
\text { rating, the better. }\end{array}$ \\
\hline Cost of energy & energyCost & Ordinal & $\begin{array}{l}1 \text { if firm rated drying cost of energy; } 5 \text { if firm rated cost of energy highest. The lower the } \\
\text { rating, the better. }\end{array}$ \\
\hline Profitability & profit & Ordinal & $\begin{array}{l}1 \text { if firm rated profitability lowest; } 5 \text { if firm rated profitability highest. The higher the rating, } \\
\text { the better. }\end{array}$ \\
\hline
\end{tabular}

(Sangeeta and Rakesh, 2018). Therefore, to examine the effect of processors' perceptions on the usage of flash dryers, Equation 7 was estimated using the logit model.

$$
\begin{aligned}
\text { Fduse }= & f(d r y E f f, \text { dryEff, uniformDry, costEff, oquality, } \\
& \text { costLab, energyCost })
\end{aligned}
$$

Descriptions of the variables used in the model are presented in Table 1. The hypothesis that processors' perceptions on the performance of flash dryers do not affect the usage (or otherwise) of flash dryers was tested using a probability value ( $p$-value) at $5 \%$ and $10 \%$ levels of significance, where an exogenous variable is significant if $p<0.05$ (or 0.10 ).

\section{DISCUSSION OF RESULTS}

Aside from the profiles of respondents, the results are presented under different categories as identified in the objectives of the study. These are the experiences in using a cassava flash dryer, technical parameters and performance of the cassava flash drying equipment, market prospects, and willingness to pay for improvements to existing flash dryers.

\section{Profiles of Respondents}

Of the 41 processing firms surveyed, only one did not complete the interview even after several visits. Data from the 40 firms that completed the interview were used for the study. However, to estimate the number of firms that are still using a flash dryer or otherwise, all 41 firms were considered. The georeferenced locations of the processing firms in the five states, as captured with GPS coordinates during the survey, are presented in Figure 2.

The respondents were either owners of the processing firms, technical managers, or senior management staff. Specifically, $60 \%$ of the respondents were owners of the firms. The mean age of the respondents was $50 \pm 11$ years. This age group represents an active workforce capable of handling technical innovation. The majority (57\%) of the respondents adopted flash dryers between 2002 and 2010, 11\% adopted the technology between 1993 and 2001, and the rest (32\%) did so between 2011 and 2019. Thus, it can be inferred that flash dryers began gaining popularity in Nigeria around 1993. The adoption seems to be in the decline as $11 \%$ adopted it at the initial stage (1993-2001). The climax (57\%) came between 2002 and 2010, while the period between 2011 and 2019 witnessed a decline to $32 \%$. If this downward trend is not checked through innovations, the flash drying technology may be extinct in Nigeria in the near future.

Furthermore, the results suggest that there are no largescale capacities ( $\geq 100$ ton of flour or starch/day) in the survey area. Small scale $(<10$ ton/day) is the most common size, according to $89 \%$ of the respondents; for $11 \%$ of the respondents, medium scale (10-100 ton/day) is the common capacity. Thus, any innovation that improves the design of energy- and costefficient small-scale flash dryers in Nigeria will have wide beneficiaries, including cost reduction benefits in countries that are importing flash dryers from Nigeria. In any case, large-scale production or many more small-scale productions may be required to achieve the needed breakthrough in the cassava and starch flour market in several cassava-producing tropical countries.

\section{Flash Dryers: Frequency of Usage and Reasons for Non-Usage}

Sixty-four flash dryers were owned by the 40 processing firms surveyed. About $58 \%$ of the firms had only one flash drying equipment, about $32 \%$ had two flash dryers, $5 \%$ had three flash dryers, while about $5 \%$ had four flash dryers (Table 2). This may have severe implications on the sustainability of production since only a few of the firms have backup equipment in the event of machine breakdown. Most firms that demand HQCF or dried starch are concerned about the consistency and sustainability of the supply of these industrial raw materials. Where the processors of HQCF or dried starch cannot guarantee the sustainability of supply, the end users may 


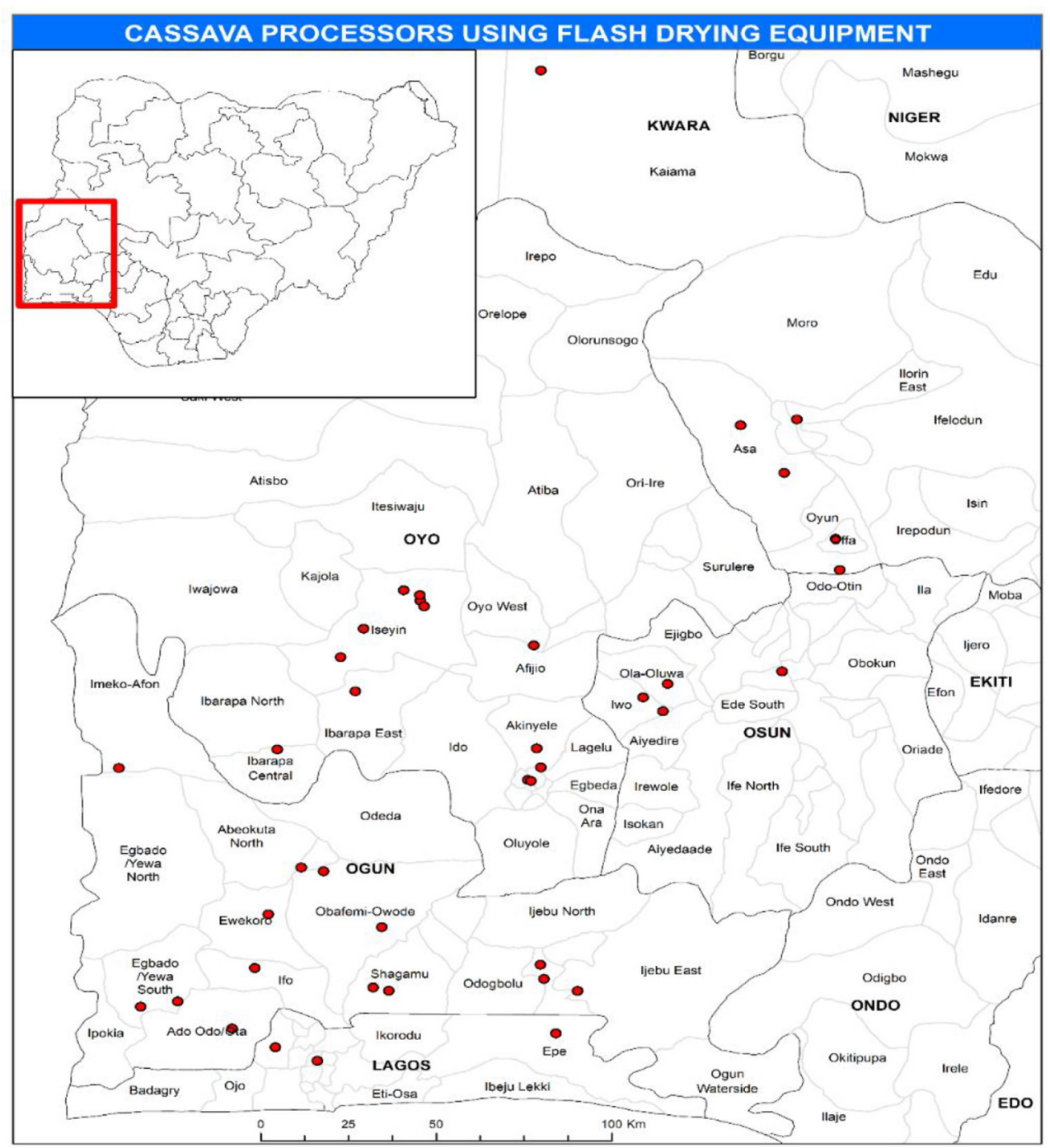

FIGURE 2 | Cassava processors with flash drying equipment. Source: Survey by the authors (November and December 2019).

be compelled to seek alternative inputs, which, in most cases, is importation.

Among the 64 flash dryers surveyed, about $48 \%$ were still in use at the time of the study, while 21 out of the 41 processors were still using flash dryers. Furthermore, as depicted in Table 2, of the $58 \%$ of processors (i.e., 24 firms) who had only one flash dryer, $50 \%$ of their flash dryers were no longer in use. Similarly, of the $32 \%$ (13 firms) who had two flash dryers, $50 \%$ of the flash dryers were no longer operational. The two processors with three flash dryers were not using any of them. Of the two firms that had four flash dryers, one used all of the dryers, while the other used three. Ogun State and Oyo State had the highest number of processors, with totals of 14 and 13, respectively (Table 2). Coincidentally, eight processors were still using flash dryers in each of the two states. In Kwara State, only one was still using a flash dryer out of the five processors.
The frequency of usage varied among processing firms from daily to not at all (Figure 3). Among the flash dryers surveyed, only about $28 \%$ were being used daily, $5 \%$ were used weekly, $5 \%$ were used monthly, 32\% were used occasionally, and 30\% were no longer used. Firms closer to urban markets such as Lagos may be expected to produce more to meet a larger demand; however, our results did not confirm this, as the geographic locations of the firms did not appear to affect the frequency of usage (Figure 3). Therefore, other factors may be at play, such as the supply and distribution networks developed by each firm individually, which can facilitate access to lower-priced raw materials and steady outlets for products regardless of the location of the firm.

The main reason for the non-usage or occasional usage of flash dryers was that, for several processors, production was only based on demand or contract $(22.5 \%)$, while others have no demand (20\%) (Figure 4). Other reasons include poor or no 
TABLE 2 | Number of flash dryers in use.

\begin{tabular}{lcc}
\hline $\begin{array}{l}\text { No. of flash } \\
\text { dryers } \\
\text { owned (A) }\end{array}$ & $\begin{array}{c}\text { Processors } \\
\% \text { of total processors }\end{array}$ & $\begin{array}{c}\text { Flash dryers } \\
\% \text { of the total being } \\
\text { used by processors }\end{array}$ \\
\hline 1 & 58.5 & 50 \\
2 & 31.7 & 50 \\
3 & 4.9 & 0 \\
4 & 4.9 & 87.5 \\
Total & 100 & 50 \\
\hline
\end{tabular}

State distribution of processors with flash dryers

State Total no. of processors

$\%$ of processors with flash dryers still in operation

\begin{tabular}{lcc}
\hline Kwara & 5 & 20.0 \\
Lagos & 3 & 33.3 \\
Ogun & 14 & 57.1 \\
Osun & 5 & 40.0 \\
Oyo & 13 & 61.5 \\
\hline
\end{tabular}

implementation of government policy on HQCF (15\%) and the high cost of production (15\%). The Nigerian government had championed a policy stipulating that all wheat flour used in the bakery industry must contain at least $10 \%$ of HQCF. This policy aimed to support the production of HQCF as a way to drive demand for smallholder cassava production and, at the same time, to reduce the trade deficit linked to the import of wheat flour. It was hoped that this policy would create a high demand for HQCF as a partial substitute for imported wheat flour and create about 80,000 employment opportunities (Abayomi and Adegoke, 2016). The processors particularly identified the cost of firing the burner and heat exchanger system as a major factor that increases the overall cost of production, making the price of HQCF higher in some cases than that of imported wheat flour. This is agreement with Ampah et al. (2017), who asserted that at least $34 \%$ of the heat energy released by fuel during combustion is lost in the heat exchanger. It also agrees with Lamboll et al. (2018), who concluded that policy changes, demand and supply of HQCF, and the supply and cost of energy are among the major sources of uncertainty in high-quality cassava flour value chains in Nigeria.

Twenty-two flash dryers were identified to have been funded by with loans, but only $36 \%$ of the firms that got loanfunded flash dryers could meet the financial commitment and repayment plan. Failure in meeting the financial commitment and repayment plan could be a result of the irregular use of the machines. This development could scare investors in this important agricultural sub-sector, unless a holistic approach is employed to ensure the viability of the flash dryer innovation. According to the respondents, some financial institutions, government agencies, and intervention projects may be willing to finance the purchase of flash drying equipment. These include the Bank of Agriculture (BOA), Bank of Industry (BOI), the African Development Bank (AfDB) intervention project, Bill Gates Foundation Intervention Project, commercial banks, cooperatives, and the Federal Government Intervention Fund (loan). Interventions from agricultural-based research organizations, such as the International Institute of Tropical Agriculture (IITA) Ibadan, Nigeria, the Federal Institute of Industrial Research, Oshodi (FIIRO), Lagos, Nigeria, and other related national and international non-governmental organizations (NGOs), have also supported projects to develop the flash drying technology. Others include the Cassava Farmers Association, International Finance Company (IFC), NISRAL Microfinance Bank, and World Bank intervention projects.

\section{Performance of Flash Dryers}

In a typical flash dryer, the drying column carries the hot conveying air and the wet grits (dewatered cassava mash) from the feeding compartment to the cyclone, during which time drying occurs. The cyclone is basically responsible for separating the hot air stream from the dried cassava flour (Figure 5).

Although there is no consensus on what should be the design of a small-scale flash dryer, Chapuis et al. (2018) suggested design guidelines for an energy-efficient flash dryer, which included the following: a flash drying pipe length greater than $20 \mathrm{~m}$, with air velocity of $10-15 \mathrm{~m} / \mathrm{s}$, air temperature of $180^{\circ} \mathrm{C}$, and an air/starch ratio of 9:11. Flash dryers were designed to have different numbers of cyclones. In the study, the number of cyclones was arbitrarily chosen to identify the flash dryers, although it may not necessarily be linked to drying efficiency. Thus, the respondents identified the model of their flash dryers based on the number of cyclones. The survey results revealed that $74 \%$ of the flash dryers owned by the surveyed firms had one cyclone, $21 \%$ had six cyclones, and the rest had two cyclones. The mean cost of 10 flash dryers purchased between 2016 and 2019 inclusive was 7,805,000 NGN (US \$21,680), ${ }^{1}$ with a standard deviation of N2,955,640 (US $\$ 8,210$ ). In the estimation, the sizes and configurations were assumed to be the same and the net present value (NPV) was not considered. This estimated cost only gives a fair idea of the costs of purchasing a standard small- or medium-scale flash dryer within the Western Region of Nigeria, at the time of the survey. When foreign exchange rates were considered, this cost was clearly cheaper (in local currency) than the prevailing price in Nigeria in 2008, when most imported flash dryers cost about US $\$ 68,500$ per unit and those locally manufactured cost about US $\$ 22,800^{2}$ per unit (IITA, 2008).

The heat exchangers of about $41 \%$ of the flash dryers were diesel-fired, about $18 \%$ were fired by the "combination of used oil (black oil) and kerosene," while 11\% were fired with "used oil" (black oil, used automobile engine oil) only (Figure 6). Interestingly, some of the processors found using firewood and coal for heat more economical.

The installed production capacity (kilograms of HQCF per day) of the 61 surveyed dryers ranged from 100 to $20,000 \mathrm{~kg} /$ day; 3 flash dryers were omitted (Figure 7). The distribution showed

\footnotetext{
${ }^{1}$ Exchange rate as of December 2019: US $\$ 1=360.00$ NGN (Central Bank of Nigeria, 2020).

${ }^{2}$ Exchange rate as of December 2008: US $\$ 1=117.81$ NGN (Central Bank of
} Nigeria, 2020). 


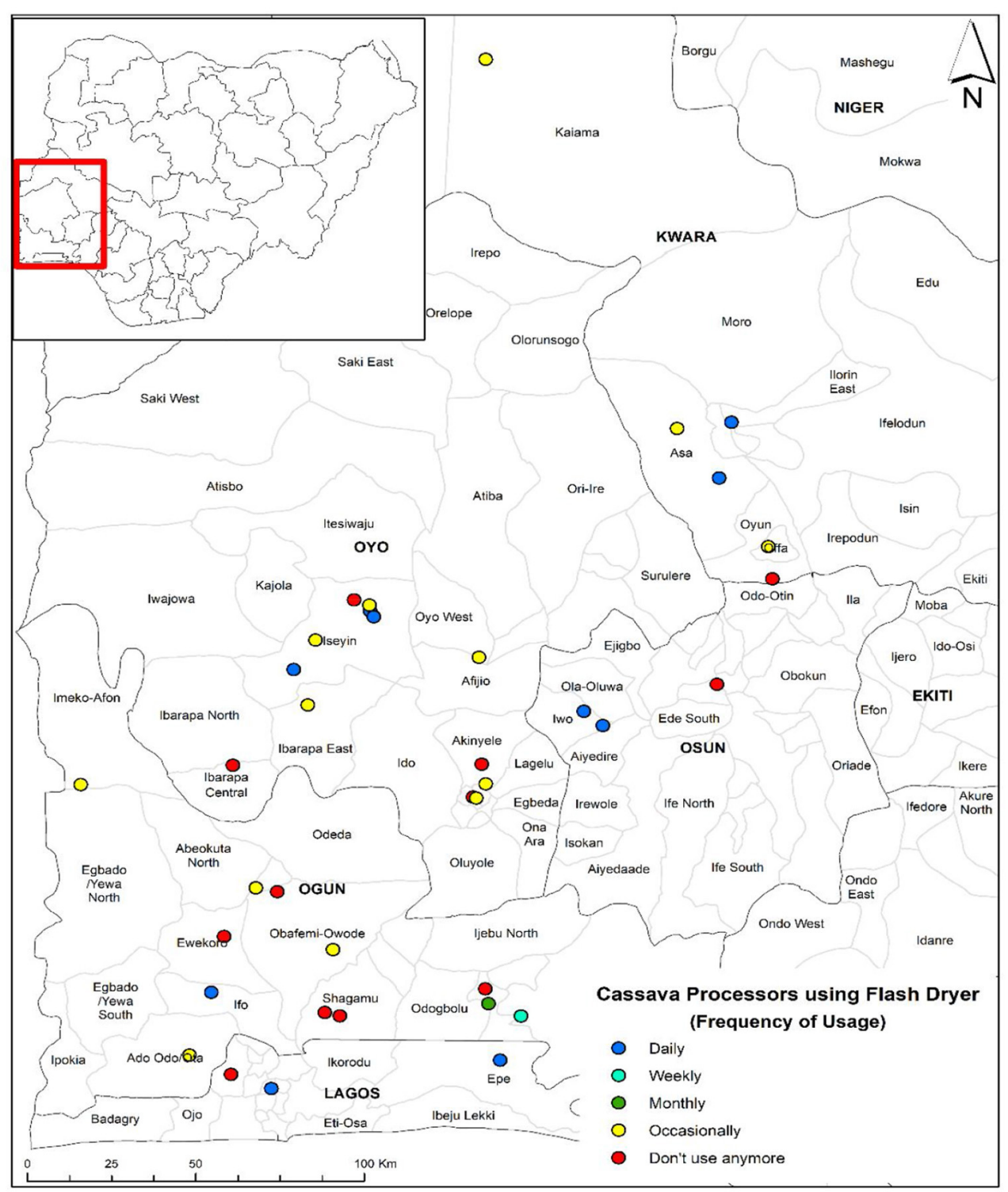

FIGURE 3 | Cassava processors using flash dryers (frequency of usage).

that most $(60 \%)$ of the dryers had installed production capacity ranging between 501 and 3,000 $\mathrm{kg} /$ day. However, the processors noted that they had challenges that barred them from producing at the installed capacities. Major among these challenges is the lack of regular and high demand for the products.

The respondents ranked the performance of the flash dryers based on certain indicators on a scale of 1-5, with 1 as the lowest and 5 as the highest (Table 3). About $71 \%$ of the flash dryers were ranked high and very high in drying efficiency. Note that, in the context of processors in this study, drying efficiency implies that the product is sufficiently dried after the cyclone(s), even though the energy consumption and/or production costs may be too high. This is unlike that in the context of process engineers, where the drying efficiency means optimized energy consumption and production costs. Thus, majority (71\%) of the processors expressed satisfaction with the drying efficiency of the machines. Table 3 also shows that $86 \%$ of the flash dryers were ranked high and very high in the uniform drying of products, while $51 \%$ were ranked average or below in cost effectiveness. About 53\% were ranked high in the overall quality of the final product, and $\sim 55 \%$ were ranked high in terms of cost of labor, while $51 \%$ were ranked high and very high in terms of the cost of energy. The high costs of labor and energy reduce profitability. Therefore, a flash dryer with energy efficiency and automated feeding and discharging systems will most likely enhance profitability. Generally, about $77 \%$ of the processors engaged $2-4$ technicians to operate a flash dryer; this excludes labor for other non-drying activities during cassava processing. 


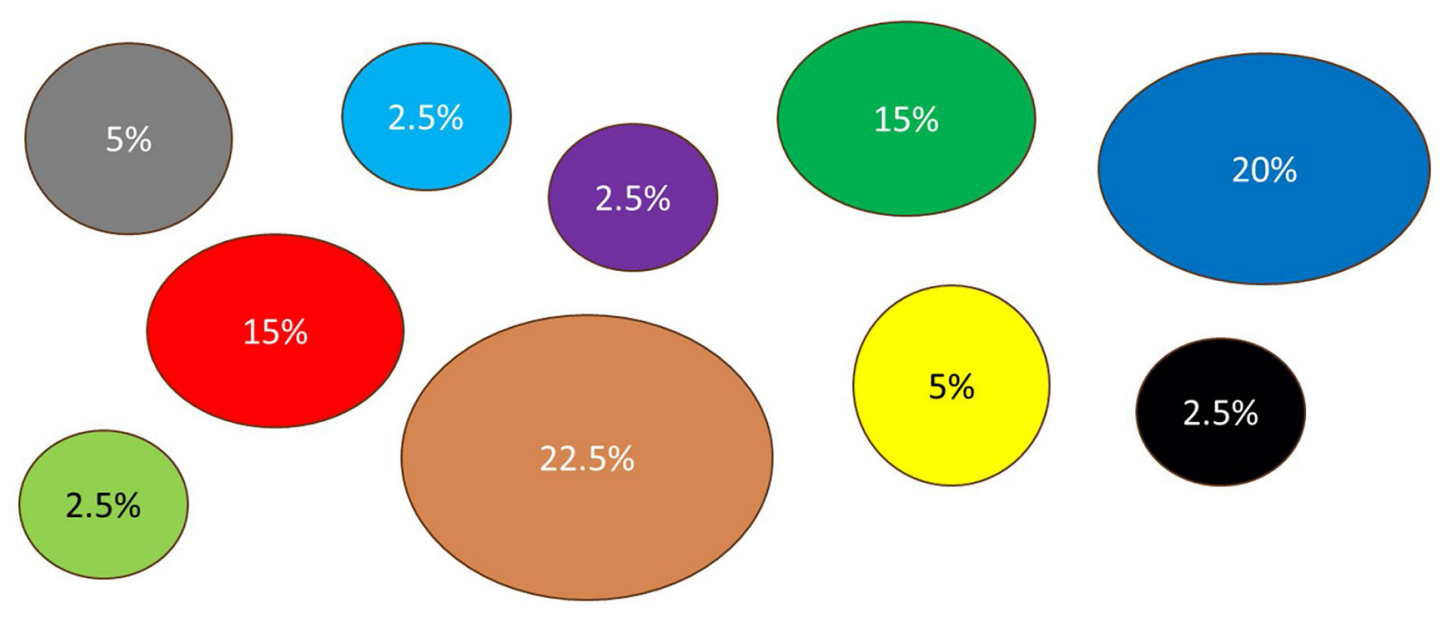

\begin{tabular}{|l|l|}
\hline & Based on demand or contract \\
\hline & No demand for HQCF \\
\hline & Low demand for HQCF \\
\hline & The cost of production (especially, for firing heat exchanger) is very high. \\
\hline & Mismanagement problem \\
\hline & Power generator had a problem \\
\hline & It is outdated. \\
\hline & The flash dryer needs renovation \\
\hline & The heat exchanger often had a fault. \\
\hline & Cassava tuber is not often available. \\
\hline
\end{tabular}

FIGURE 4 | Reasons for the non-use (or occasional usage) of flash dryers.

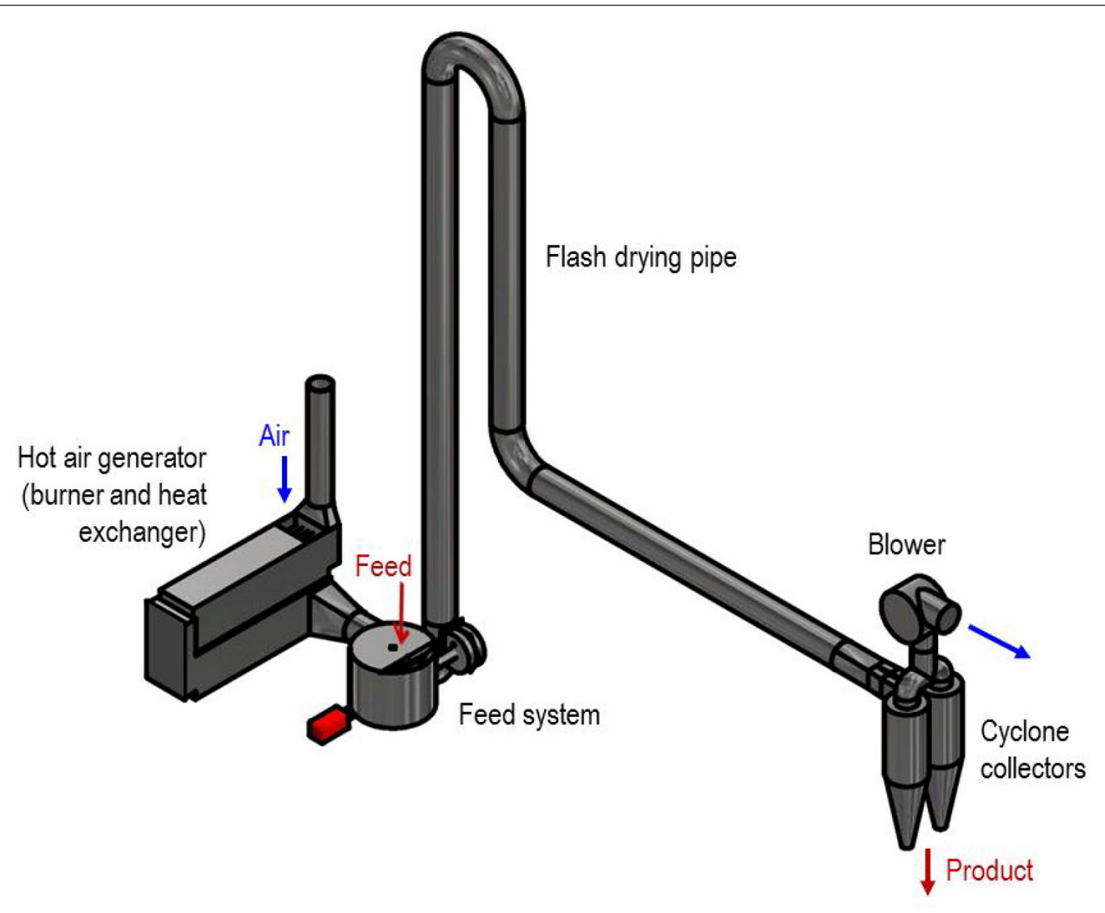

FIGURE 5 | Key components common to all flash dryer designs (source: Authors). 


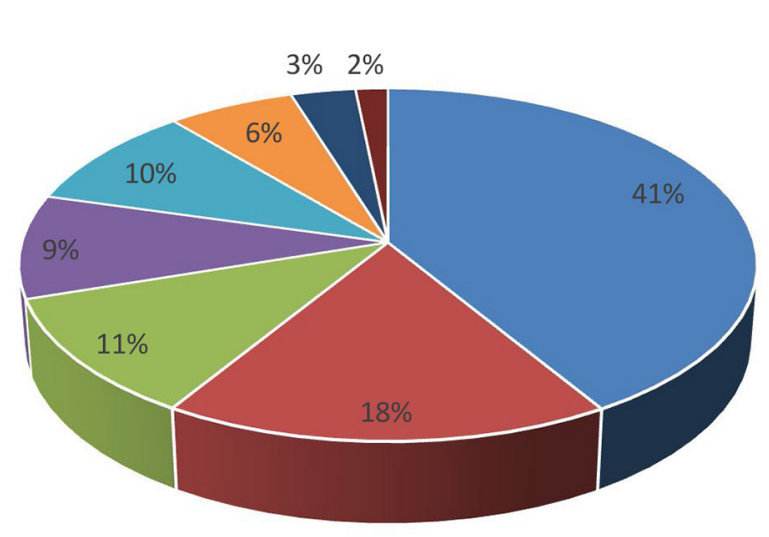

- Diesel

- Used oil (black oil) cum

kerosene or petrol

- Used oil (black oil)

- Wood

- Others (including coal, \& a

combination of coal \&

wood)

- Electricity

FIGURE 6 | Energy source for heat exchanger-frequency.

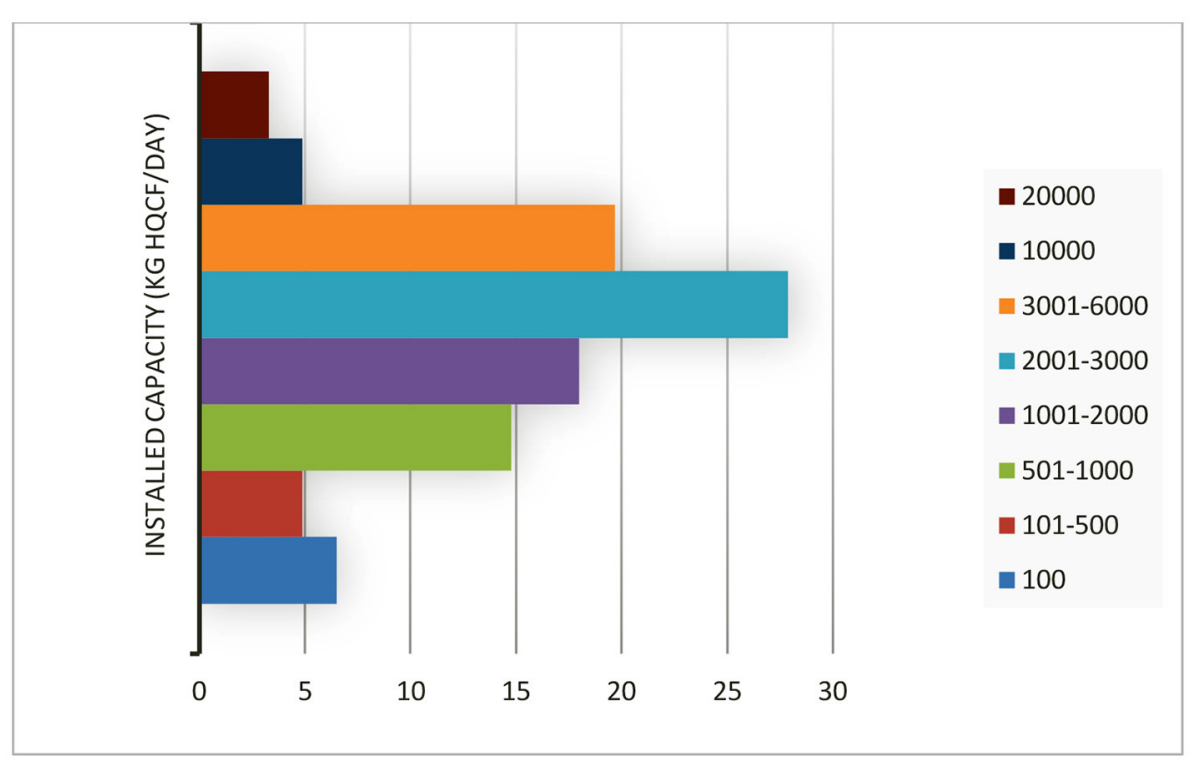

FIGURE 7 | Percentage distribution of installed production capacity (kg HQCF/day). HQCF, high-quality cassava flour.

TABLE 3 | Perceptions of processors of the performance of flash dryers.

\begin{tabular}{lccccc}
\hline Indicator & Very low & Low & Average & High & Very high \\
\hline Drying efficiency & - & 5.5 & 23.6 & 36.4 & 34.5 \\
Uniform drying of the product & - & 5.3 & 8.8 & 36.8 & 49.1 \\
Cost effectiveness & 9 & 16 & 26 & 31 & 18 \\
Overall quality of the final product & - & 3.5 & 5.3 & 52.6 & 38.6 \\
Cost of labor & 5.3 & 5.3 & 35.1 & 45.6 & 8.8 \\
Cost of energy & 1.7 & 13.8 & 32.8 & 43.1 & 8.6 \\
Profitability & 8.8 & 21.1 & 21.1 & 31.6 & 17.5 \\
\hline
\end{tabular}

A logistic regression model was estimated to ascertain whether these indicators (processors' perceived performance of flash dryers) have a significant effect on the continuous usage of flash dryers or otherwise (Table 4). The overall logistic regression model was significant (Prob. $>\chi^{2}=0.00$ ). Among the seven measurements of the processors' perceptions about flash dryers, cost effectiveness $(p<0.05)$ and energy costs $(p<0.10)$ were found to be statistically significant. As expected, cost effectiveness was positively associated with the usage of flash dryers, while energy cost was negatively related to their use. This implies that the higher a processor rates the cost effectiveness of any machine, the higher the probability of continuous usage of flash dryers.

On the other hand, the higher a processor rates the energy costs of any flash dryer, the higher the probability that the flash dryer will no longer be used. These results agree with the TAM associated with Davis (1986), as cited in Lai (2017), which stipulated that the perceived usefulness of a technology determines its adoption (or otherwise). Table 3 shows that about 
TABLE 4 | Logistic regression estimation of flash dryer usage with reference to users' perceptions.

\begin{tabular}{|c|c|c|c|c|}
\hline Flash dryer usage & Coefficient & Odds ratio & $z$ & $p$-value \\
\hline Dryeff & $-1.49(0.94)$ & $0.22(0.21)$ & -1.58 & 0.11 \\
\hline Uniformdry & $0.80(0.84)$ & $2.22(1.88)$ & 0.95 & 0.34 \\
\hline Costeff & $3.35(1.36)^{\star \star}$ & 28.55 (38.70) & 2.47 & 0.01 \\
\hline Oquality & $1.47(0.98)$ & $4.35(4.26)$ & 1.50 & 0.13 \\
\hline Costlab & $0.29(0.89)$ & $1.33(1.18)$ & 0.32 & 0.75 \\
\hline Energycost & $-1.97(1.13)^{\star}$ & $0.14(0.16)^{\star}$ & -1.74 & 0.08 \\
\hline Profit & $0.54(0.64)$ & $1.72(1.11)$ & 0.84 & 0.40 \\
\hline _cons & $-10.95(5.22)^{\star \star}$ & $0.00(0.00)^{\star \star}$ & -2.10 & 0.04 \\
\hline \multicolumn{2}{|c|}{$\operatorname{LR} \chi^{2}(7)=47.39$} & \multicolumn{3}{|c|}{ Prob. $>\chi^{2}=0.00$} \\
\hline \multicolumn{2}{|c|}{ Log-likelihood $=-12.96$} & \multicolumn{3}{|c|}{ Pseudo- $R^{2}=0.65$} \\
\hline
\end{tabular}

Standard error values are in parentheses.

$L R$, logistic regression.

${ }^{*}$ Significant at $5 \%$; ** significant at $10 \%$.

$71 \%$ of the flash dryers were ranked high and very high in drying efficiency, but the regression results in Table 4 show that the perceived drying efficiency is not a significant factor in determining whether a processor will continue to use flash dryers or otherwise. Rather, optimized energy consumption and production costs are the significant factors.

\section{Market Prospects of High-Quality Cassava Flour}

Figure 8 shows the factors influencing the production of HQCF, in order of importance. The two prominent factors are price and quality. Following the basic microeconomic principle, this implies that, if the price of HQCF is relatively high, processors will increase supply by increasing production levels (Mas-Colell et al., 1995). On the other hand, if the quality of HQCF is high relative to the major alternative product (wheat flour), end users of HQCF will increase their demand, which will lead to an increase in the production level. According to Abayomi and Adegoke (2016), most small- and medium-scale producers in Nigeria struggle to deliver HQCF that meets quality specifications.

Amaza et al. (2016) opined that mechanized postharvest processing of cassava into HQCF is influenced by access to the product market. Figure 9 shows that the primary buyers of HQCF are wheat flour millers (about 44\%) and baking industries (about 22\%). The processors opined that they are at the mercy of the wheat flour millers who, in most cases, determine the price of the product. Most of the flour millers deal in imported wheat grains, which they mill to flour. Thus, stakeholders in the production of HQCF in Nigeria need to ensure that the production costs of HQCF are relatively lower than the cost of imported wheat flour in the country. If this is achieved, HQCF processors will express market expansion.

The survey results further showed that about $62 \%$ of the respondents opined that HQCF is currently not competitive enough to warrant end users to switch from wheat flour to

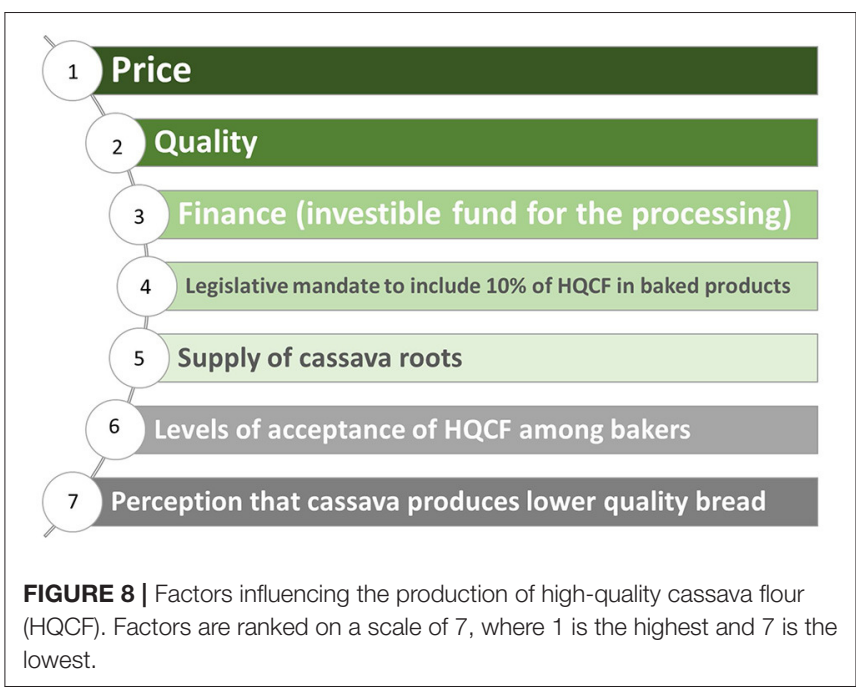

HQCF/wheat composite flour. Processors observed that the main factors that make HQCF less competitive are the low demand for HQCF by wheat flour millers and bakers, cassava being more starchy than wheat, and the government policy on HQCF not being enforced (inability of the government to enforce $10 \%$ HQCF inclusion in baked products). The other factors are the low quality of HQCF produced by some processors, the certification requirements by regulatory agencies, negative perception of consumers about cassava flour in baked products, poor equipment design, and the high cost of transporting roots over a long distance to processing factories, being bulky and perishable. Another challenge is that bulk buyers of HQCF demand for 30 ton (one trailer) or even 60 ton (two trailers) per supply, whereas most flash dryers have a production capacity of less than 3 ton of HQCF per day. As a result, most processors cannot fulfill such large supply orders. This suggests that several small- and medium-scale processors may need to form cooperatives to meet such high demand within the stipulated time. Such business cooperation could enhance their ability to meet the large demand of the industry and increase their access to the market niche.

\section{Willingness of the Processors to Pay for Improvements in the Drying and Energy Efficiency of Existing Flash Dryers}

Forty-one percent of the processors indicated the willingness of their firms to pay for improvements to their existing flash dryers, supposing such improvement will increase the drying and energy efficiency of the equipment by $40 \%$. Fifty-nine percent were not willing to pay for such adjustments (Figure 10). The average amount proposed by the willing firms to pay for such improvements was 2,381,428 NGN (US \$6,615). Firms willing to pay for improvements were further examined on their willingness to pay beyond the proposed amount based on two scenarios: when the costs of adjustments were higher than the proposed cost by $20 \%$ and by $50 \%$ (Figure 10). Of the $41 \%$ of firms who initially indicated a willingness to pay for improvements 


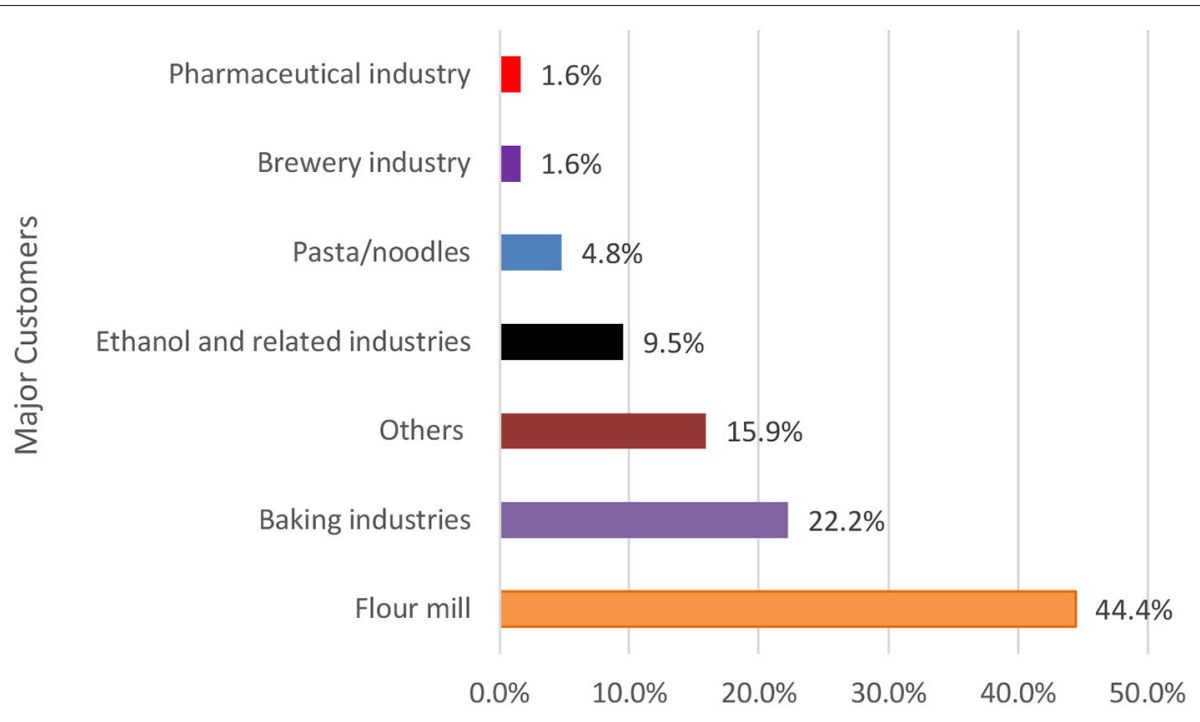

FIGURE 9 | Major buyers of high-quality cassava flour (HQCF).

to their flash dryers, $17 \%$ indicated unwillingness to pay if their initial proposed costs were higher by $20 \%$. The remaining $83 \%$ who indicated a willingness to pay if their initial proposed costs were higher by $20 \%$ were classified into two categories: $25 \%$ who were still willing to pay if their initial proposed costs were rather higher by 50 and $58 \%$ who were no longer willing to pay if their initial proposed costs were higher by $50 \%$. The willingness of the firms to pay for improvements to their existing flash dryers is a clear indication that most of them were eager to adopt technological innovations that will enhance their productivity.

Respondents who indicated an unwillingness to pay for improvements to their existing flash dryers provided the following five major reasons for their position:

1. Evidence: they prefer to see evidence of such improvements before making an investment decision. This agrees with the theoretical framework of this study (TAM) that perceived usefulness affects investors' behavior toward technology adoption (Lai, 2017).

2. Profitability: a demonstration of the efficiency and profitability of such improvements will be required.

3. Price of HQCF: the price of HQCF is affected by policy, which they opined is not favorable. Failure of the government to promote the market for HQCF was blamed. The investors suggested that enforceable laws should back government efforts toward promoting the use of HQCF.

4. Subsidy: the processors suggested that the government should demonstrate its commitment toward promoting the use of HQCF by granting subsidies for such improvements, considering that they (the processors) have already made a heavy investment in the dryers.

5. Production cost: the cost of production is very high. A significant reduction in the cost of firing a heat exchanger is required.

\section{CONCLUSION}

This study was carried out to ascertain the current situation and perceptions of the users of flash dryers in Nigeria in order to facilitate the benchmarking of future developments in the sub-sector and any improved experience among end users of small- and medium-scale flash dryers in Western Nigeria. The participants in the study were processors who own flash dryers-functional and non-functional-in Lagos, Oyo, Ogun, Kwara, and Osun States. The study examined the experiences of processors in the use of flash dryers, the technical parameters and performance of the equipment, market prospects, and the willingness of the processors to pay for improved cassava flash dryers.

Generally, small-scale ( $<10$ ton/day) flash dryers were found to be common (89\%) among the firms. At the firm level, $49 \%$ of the processors surveyed were no longer using their flash dryers. This was attributed, primarily, to the low demand for HQCF. Price and quality were the two major factors that influenced the demand for HQCF. Naturally, the price of HQCF would have been more competitive if the costs of processing had been lower. The processors rely primarily on wheat flour millers (about $44 \%$ ) for the sale of HQCF. Forty-one percent of the processing firms indicated a willingness to pay for any adjustments to their current flash dryers, provided such adjustments would improve the drying and energy efficiency of the equipment up to $40 \%$. Unwilling firms were likely to change their position if such improvements can be demonstrated.

The study, therefore, recommends that fabricators (equipment manufacturers) of flash dryers in Nigeria and other African countries should be trained on the production of energy- and cost-efficient small-scale flash dryers-especially dryers with a low fuel consumption rate. Research institutions may also consider the design and commercialization of flash dryers that can be mounted on mobile trucks for farm-gate 


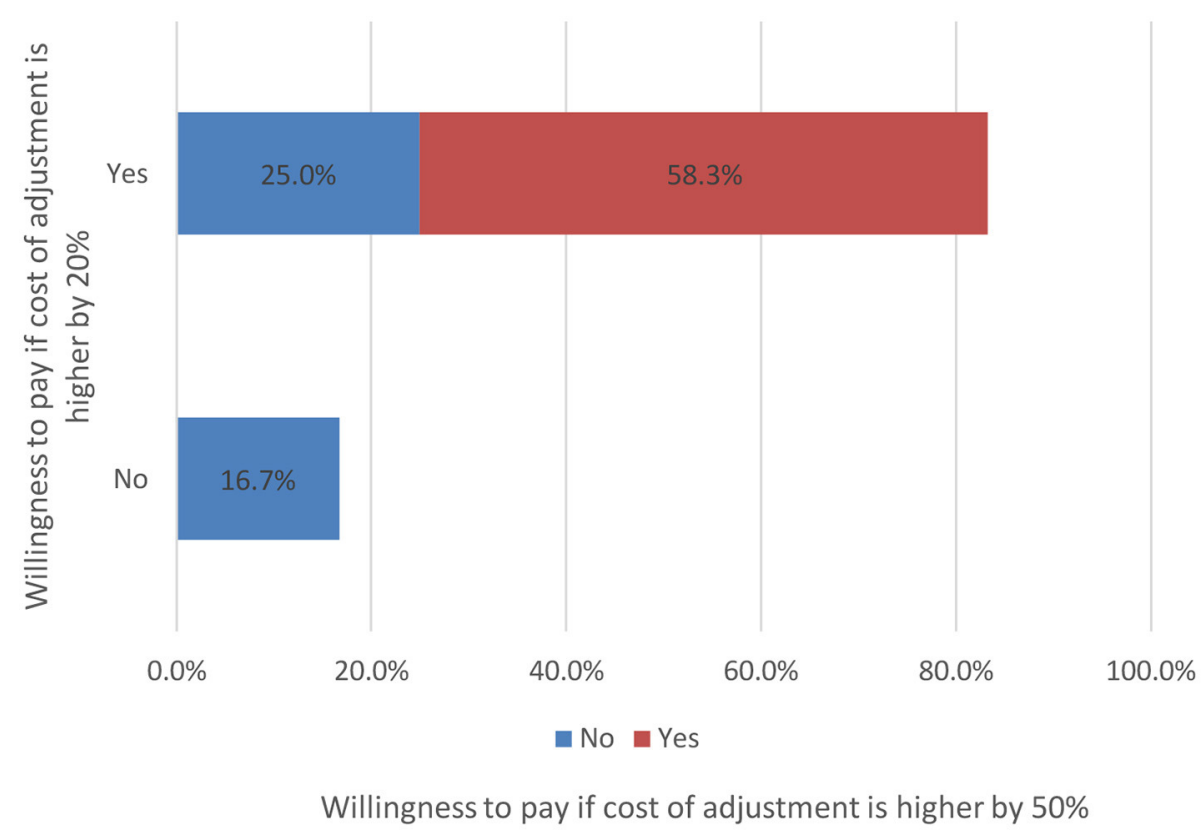

FIGURE 10 | Willingness to pay if the costs of adjustments were $20 \%$ and $50 \%$ above the respondents' initial proposed costs.

processing. The introduction of such viable small-scale mobile drying units will be a major achievement in reducing postharvest losses and cost of transportation as the processors can process large quantities of cassava roots at the farm gate, thereby avoiding the need to transport perishable and bulky roots over a long distance. In addition, clusters of processors with standardized quality products can collaborate in order to meet bulk orders from large buyers.

The following policies were suggested:

i. Market component: fortify the HQCF value chain to control the costs of raw materials (cassava roots) and increase market opportunities for HQCF processors. Agricultural extension agencies should coordinate and strengthen collaborations among processors using the flash drying technology to help them gain market influence, for instance, by pooling their production to fulfill large orders (30 ton or above). The production of alternative products such as cassava starch or flours from other roots and tubers (e.g., yams) may also be considered during times of low demand for HQCF to increase the utilization rate of flash dryers (and, hence, return on investment).

ii. Technology component: improve the energy efficiency and reduce the operating costs of flash drying systems. Agricultural research institutes and agricultural technology agencies should promote efficient flash drying equipment design and production through training and demonstration workshops using the research results and innovations of the RTB project (https://flashdryer. cirad.fr/). Research institutions such as FIIRO (Lagos) have a demonstration flash dryer installed training for training purposes. iii. Product quality component: achieve production of HQCF of stable and consistent quality to meet buyers' needs (bakery, confectionery, etc.). Small- and medium-scale producers of HQCF in Africa should be exposed to further training in quality production management and efficient operation management of flash dryers.

iv. Policy component: create incentives for the development of HQCF markets.

As more countries consider initiatives similar to Nigeria to increase the production of cassava and HQCF in order to develop their economies and reduce the importation of wheat, the above-mentioned four components (market, technology, quality, policy) must be addressed together systemically to maximize the prospects of progress.

\section{DATA AVAILABILITY STATEMENT}

The raw data supporting the conclusions of this article will be made available by the authors, without undue reservation.

\section{AUTHOR CONTRIBUTIONS}

MO was involved in the study design, led the data collection, development of the analytical tools, data analysis, and writing of the paper, and discussed the results with co-authors. SA was involved in the study design, contributed to developing the analytical tools, including the sampling method, provided critical feedback on the manuscript draft, discussed the results, and contributed to the writing of the paper. TT was involved in the research project idea and resource mobilization, led 
the project, provided overall direction, planning, and project supervision, contributed to the study design, and provided critical feedback on the manuscript draft. LT was involved in the study design, provided project support, discussed the results, and provided critical feedback. AC, SL, ET, MuS, MaS, LB, DD, and AA supervised the findings of this work, provided critical feedback, discussed the results, and contributed to the final manuscript. AA conceived the original idea, was involved in the study design, contributed to the analysis tools, verified the analytical methods, was in charge of the overall direction of the project and study, co-led the planning, and supervised the project. All authors approved the final manuscript.

\section{FUNDING}

This research was undertaken as part of the CGIAR Research Program on Roots, Tubers and Bananas (RTB)/RTB Scaling Readiness project. RTB is funded by CGIAR Trust Fund contributors (https://www.cgiar.org/funders/). Co-funding was provided by CIRAD, French Agricultural Research Centre for International Development: https://www.cirad.fr/en (Energy-efficient small-scale flash dryers for cassava processing: https://flashdryer.cirad.fr/) and the Cassava Compact of the

\section{REFERENCES}

Abass, A., Amaza, P., Bachwenkizi, B., Alenkhe, B., Mukuka, I., and Cromme, N. (2017a). Adding value through the mechanization of postharvest cassava processing, and its impact on household poverty in northeastern Zambia. Appl Econ Lett. 24, 579-583. doi: 10.1080/13504851.2016.12 13356

Abass, A., Amaza, P.;, Bachwenkizi, B., Wanda, K., Agona, A., and Cromme, N. (2017b). The impact of mechanized processing of cassava on farmers' production efficiency in Uganda. Appl. Econ. Lett. 242, 102-104. doi: $10.1080 / 13504851.2016 .1167817$

Abayomi, L., and Adegoke, A. (2016). Increasing Performance of the Cassava Industry in West and Central Africa Region (IPCI): High Quality cassava Flour (HQCF) Case Study Report. IFAD West and Central Africa Division.

Adesina, A. A., and Chianu, J. (2002). Determinants of farmers' adoption and adaptation of alley farming technology in Nigeria. Agrofor. Syst. 55, 99-112. doi: 10.1023/A:1020556132073

Africa Innovations Institute [AfrII] (2018). Flash Dryer technology eases commercial cassava processing in Northern Uganda. Available online at: https://www.afrii.org/flash-dryer-technology-eases-commercial-cassavaprocessing-in-northern-uganda/ (accessed October 12, 2020).

Ajao, K. R., and Adegun, I. K. (2009). Performance evaluation of a locally fabricated mini cassava flash dryer. J. Agricult. Technol. 5, 281-289. Available online at: http://www.ijat-aatsea.com/pdf/Nov_v5_n2_09/07-IJAT2009_19F.pdf

Amaza, P. S., Abass, A. B., Bachwenkizi, B., and Towo, E. E. (2016). Adoption of Mechanized Postharvest Cassava Processing Technologies, and the Determinants of High Quality Cassava Flour (HQCF) Processing in Tanzania. Tropicultura 34, 411-423. Available online at: https://popups.uliege.be/22958010/

Ampah, J., Dziedzoave, N., Agblo, E. T., Bempong, O., Djokoto, F., Addo, I., et al. (2017). Assessment of a 6-Cyclone Flash Dryer: Technical Report." Council for Scientific and Industrial Research - Food Research Institute (CSRI-FRI), ACCRA - GHANA.

Beeching, J. R., Marmey, P., Gavalda, M. C., Noirot, M., Haysom, H. R., Hughes, M. A., et al. (1993). An Assessment of genetic diversity within a collection of cassava (manihot esculenta crantz) germplasm
Technologies for African Agricultural Transformation (TAAT) project funded by the African Development Bank (AfDB). TAAT is led by the International Institute of Tropical Agriculture (IITA). The funds provided for this study are acknowledged with thanks.

\section{ACKNOWLEDGMENTS}

This research study was undertaken by the CGIAR Research Program on Roots, Tubers and Bananas-RTB (https://www. cgiar.org/funders/), the International Institute of Tropical Agriculture (IITA), the Alex Ekwueme Federal University Ndufu-Alike (AE-FUNAI), Ebonyi State, Nigeria, and the Federal Institute of Industrial Research, Oshodi (FIIRO), Lagos, Nigeria. The CGIAR Trust Fund contributors support RTB. In addition, the contributions of respondents during the survey are acknowledged with thanks. The substantial contributions of the co-authors are acknowledged.

\section{SUPPLEMENTARY MATERIAL}

The Supplementary Material for this article can be found online at: https://www.frontiersin.org/articles/10.3389/fsufs. 2021.771639/full\#supplementary-material

using molecular markers. Annal Bot. 72, 515-520. doi: 10.1006/anbo. 1993.1139

Chapuis, A., Precoppe, M., Méot, J. M., Sriroth, K., and Tran, T. (2017). Pneumatic drying of cassava starch: Numerical analysis and guidelines for the design of efficient small-scale dryers. Dry. Technol. 35, 393-408, doi: 10.1080/07373937.2016.1177537

Chapuis, A., Tran, T., Giraldo, F., Moreno, M., Precoppe, M., Moreno, J., et al. (2018). Development and trials of a small-capacity pilot flash dryer for cassava-derived products. A presentation made during Triennial symposium of International Society for Tropical Crops in Cali, Colombia. 22-25 October 2018.

Davis, F. D. (1986). A technology Acceptance Model for Empirically Testing New End-User Information Systems: Theory And Results. Massachusetts: Sloan School of Management, Massachusetts Institute of Technology.

IITA (2006). Developing a Nigerian-made flash dryer. Available online at: https:// www.iita.org/news-item/developing-nigerian-made-flash-dryer/ (accessed May 14, 2020).

IITA (2008). Bigger Profits, Better Product From New Cassava Flash Dryer. Available online at: https://www.iita.org/news-item/bigger-profits-better-product-newcassava-flash-dryer/ (Accessed October 14, 2020).

Johnson, E., Pemberton, C., and Seepersad, J. (1999). Adoption behaviour of private cocoa farmers in Trinidad and Tobago. Tropical Agricult. 76:2.

Kuye, A., Raji, A. O., Otuu, O. O., Kwaya, E. I., Asiru, W. B., Kareem, I. B. A., et al. (2017). Design, fabrication and drying performance of flash dryer for high quality cassava flour. Agricult. Mechanizat. Asia, Africa, and Latin Am. 48, 63-70. Available online at: https://www.researchgate. net/profile/L_Sanni/publication/321153830_Design_fabrication_and_ drying_performance_of_flash_dryer_for_high_quality_cassava_flour/links/ 5b3a5bb0aca27207850503cb/Design-fabrication-and-drying-performanceof-flash-dryer-for-high-quality-cassava-flour.pdf?origin=publication_detail

Lai, P. C. (2017). The literature review of technology adoption models and theories for the novelty technology. JISTEM J. Inform. Syst. Technol. Manage. 14, 21-38. doi: 10.4301/S1807-17752017000100002

Lamboll, R., Martin, A., Sanni, L., Adebayo, K., Graffham, A., Kleih, U., et al. (2018). Shaping, adapting and reserving the right to play: responding to uncertainty in high quality cassava flour value chains in Nigeria. J. Agribus. Develop. Emerg. Econ. 8, 54-76. doi: 10.1108/JADEE-03-2017-0036 
Mas-Colell, A., Whinston, M., and Green, J. (1995). Principles of Microeconomics. Oxford: Oxford University Presss, p. 138.

Oregon State University (2010). Snowball Sampling. Availale online at: https:// research.oregonstate.edu/irb/policies-and-guidance-investigators/guidance/ snowball-sampling (accessed May 15, 2020).

Precoppe, M., Chapuis, A., Müller, J., and Abass, A. (2017). Tunnel dryer and pneumatic dryer performance evaluation to improve small-scale cassava processing in Tanzania. J. Food Process Eng. 40, e12274. doi: 10.1111/jfpe.12274

Precoppe, M., Komlaga, G. A., Chapuis, A., and Müller, J. (2020). Comparative study between current practices on cassava drying by small-size enterprises in Africa. Appl. Sci. 10, 1-17. doi: 10.3390/app10217863

Precoppe, M., Tran, T., Chapuis, A., Müller, J., and Abass, A. (2016). Improved energy performance of small-scale pneumatic dryers used for processing cassava in Africa. Biosyst. Eng. 151, 510-519. doi: 10.1016/j.biosystemseng.2016.10.001

Runyi, E. F. (2017). The application of binary logistic regression analysis on staff performance appraisal. Sci. J. Appl. Math. Stat. 5, 164-168. doi: $10.11648 / j . s j a m s .20170504 .15$

Sangeeta, T., and Rakesh, M. J. (2018). Building and evaluating logistic regression models for explaining the choice to adopt MOOCs in India. Int. J. Educ. Develop. Inform. Commun. Technol. 14, 33-51.

Scott, G. (2021). A review of root, tuber and banana crops in developing countries: past, present, and future. Int. J. Food Sci. Technol. 56, 1258-1277. doi: $10.1111 /$ ijfs. 14778

Shittu, T. A., Alimi, B. A., Wahab, B., Sanni, L. O., and Abass, A. B. (2016). Cassava Flour and Starch: "Processing Technology and Utilization" in Tropical Roots and Tubers: Production, Processing and Technology, First Edition., eds Sharma H. K., Njintang N. Y., Singhal R. S. and Kaushal P. New York, NY: John Wiley and Sons, Ltd.
Straub, E. (2009). Understanding technology adoption: theory and future directions for informal learning. Rev. Educ. Res. 79, 625-649. doi: 10.3102/ 0034654308325896

Wossen, T., Alene, A., Abdoulaye, T., Feleke, S., Rabbi, I., and Manyong, V. (2019). Poverty reduction effects of agricultural technology adoption: the case of improved cassava varieties in Nigeria. J. Agricult. Econ. 70, 392-407. doi: 10.1111/1477-9552. 12296

Conflict of Interest: The authors declare that the research was conducted in the absence of any commercial or financial relationships that could be construed as a potential conflict of interest.

Publisher's Note: All claims expressed in this article are solely those of the authors and do not necessarily represent those of their affiliated organizations, or those of the publisher, the editors and the reviewers. Any product that may be evaluated in this article, or claim that may be made by its manufacturer, is not guaranteed or endorsed by the publisher.

Copyright $\odot 2022$ Ojide, Adegbite, Tran, Taborda, Chapuis, Lukombo, Totin, Sartas, Schut, Becerra Lopez-Lavalle, Dufour and Abass. This is an open-access article distributed under the terms of the Creative Commons Attribution License (CC BY). The use, distribution or reproduction in other forums is permitted, provided the original author(s) and the copyright owner(s) are credited and that the original publication in this journal is cited, in accordance with accepted academic practice. No use, distribution or reproduction is permitted which does not comply with these terms. 